Int. J. Electrochem. Sci., 12 (2017) 10958 - 10968

\title{
Electrochemical Synthesis of PtNiCo/3DGN Composite Catalyst and Its Performance for Methanol Electrooxidation
}

\author{
Zhenyu Wang ${ }^{1}$, Feifei Zhang ${ }^{1, *}$, Qingyun Liu ${ }^{2}$ and Zonghua Wang ${ }^{1}$ \\ ${ }^{1}$ College of Chemistry and Chemical Engineering, Laboratory of Fiber Materials and Modern \\ Textile, The Growing Base for State Key Laboratory, Shandong Sino-Japanese Center for \\ Collaborative Research of Carbon Nanomaterials, Qingdao University, Qingdao 266071, China \\ ${ }^{2}$ College of Chemistry and Environmental Engineering, Shandong University of Science and \\ Technology, Qingdao 266590, China \\ *E-mail: zhangfeifei00921@126.com
}

doi: $10.20964 / 2017.11 .78$

Received: 15 July 2017 / Accepted: 16 September 2017 / Published: 12 October 2017

A novel PtNiCo/three-dimensional graphene (PtNiCo/3DGN) catalyst was synthesized by sequential electrodeposition of three-dimensional graphene and PtNiCo nanoparticles. The catalysts were characterized by scanning electron microscopy (SEM), transmission electron microscopy (TEM), Raman and electrochemical measurements. Electrochemical experiments revealed that PtNiCo/3DGN catalyst shows high activity for methanol oxidation with improved electrocatalytic capacity (the forward anodic peak current density of $790.4 \mathrm{~mA} \mathrm{mg}_{\mathrm{Pt}}{ }^{-1}$ ), which is about 2.02 and 2.06 folds of that for $\mathrm{PtNi} / 3 \mathrm{DGN}\left(390.2 \mathrm{~mA} \cdot \mathrm{mg}^{-1}{ }_{\mathrm{Pt}}\right)$ and $\mathrm{PtCo} / 3 \mathrm{DGN}\left(383.9 \mathrm{~mA} \cdot \mathrm{mg}^{-1}{ }_{\mathrm{Pt}}\right)$, and much higher than $\mathrm{Pt}(144.0$ $\left.\mathrm{mA} \cdot \mathrm{mg}^{-1}{ }_{\mathrm{Pt}}\right)$ and $\mathrm{Pt} / 3 \mathrm{DGN}\left(277.2 \mathrm{~mA} \cdot \mathrm{mg}^{-1}{ }_{\mathrm{Pt}}\right)$ catalysts.

Keywords: Methanol oxidation; Three-dimensional graphene (3DGN); PtNiCo nanoparticles; Electrodeposition

\section{$\underline{\text { FULL TEXT }}$}

(C) 2017 The Authors. Published by ESG (www.electrochemsci.org). This article is an open access article distributed under the terms and conditions of the Creative Commons Attribution license (http://creativecommons.org/licenses/by/4.0/). 